\title{
Original
}

\section{HPLC Determination of Pheophorbide $a$ and Pyropheophorbide $a$ in Dried Laver Product Implicated in Food Poisoning}

(Received September 28)

\author{
Deng-Fwu Hwang*1, ${ }^{\dagger}$, Yu-Shia TsaI*1, Shin-Shoug Chou*2, Shiu-Mei LiU*3, \\ Jiunn-Tzong $\mathrm{WU}^{* 4}$, Shin-Jung LiN ${ }^{* 5}$ and Wei-Chun Tu*1 \\ (*1 Department of Food Science, National Taiwan Ocean University: 2 Pei-Ning Road, Keelung 202, \\ Taiwan, R.O.C.; *2 National Laboratories of Food and Drugs, Department of Health, \\ Executive Yuan: 161-2 Kuen Yang St., Nankang, Taipei, Taiwan, R.O.C.; \\ *3 Institute of Marine Biology, National Taiwan Ocean University: 2 Pei-Ning Road, \\ Keelung, Taiwan, R.O.C.; *4 Institute of Botany, Academia Sinica: 128 2Sec, \\ Kankung Road, Nankang, Taipei, Taiwan, R.O.C.; ${ }^{* 5}$ Department of Food \\ Science and Technology, Ching-Kuo Institute of Management and Health: \\ 336 Fu-Hing Road, Keelung, Taiwan, R.O.C.: ${ }^{\dagger}$ Corresponding author)
}

In an outbreak of food poisoning involving a dried purple laver product (called nori), four persons had allergic-like symptoms such as inflammation and red rash on their face, mouth and belly. The causative nori was extracted and smeared on the arm-skin of five volunteers. Three out of five volunteers had a slight allergic reaction after 5 to $30 \mathrm{~min}$ when they were exposed to sunlight. The levels of the chlorophyll derivatives, pheophorbide $a$ and pyropheophorbide $a$, measured by HPLC were $851-906$ and $5,460-5,624 \mu \mathrm{g} / \mathrm{g}$, respectively, in the causative samples. Judging from the high contents of pyropheophorbide $a$ and pheophorbide $a$ and the symptoms of patients and volunteers, the causative agents were concluded to be the photosensitizers pyropheophorbide $a$ and pheophorbide $a$.

Key words: allergic symptom; dried purple laver product; nori; pyropheophorbide; pheophorbide

\section{Introduction}

A rare example of toxicity due to ingesting nori (dried purple laver product) occurred on May 9, 2001 in Taiwan. There were two patients (both female, 8 and 62 years old) who had allergic-like symptoms, such as inflammation and red rash on their face, the corners of the mouth and the belly, several hours after eating a dried laver product. Both patients were seen at a hospital and soon recovered. The event was reported to the nori company. Two company officers (male, 32 and female, 36) also individually ate a small slice of laver product and then exhibited the same allergic symptoms after 30 min. Because the symptoms were not serious, they were not hospitalized.

The major species of purple laver are Porphyra dentata and P. crispata, both of which are popular in Japan, Korea, Mainland China and Taiwan. These lavers are usually dried and sold as dried products (called nori in Japanese). Nori is rich in protein and fiber, and also contains bioactive substances, including prophyosin, eicosapentaenoic acid (EPA), antibacterial substances, taurine and $\beta$-carotene ${ }^{1}$. It is a popular health food among Asian people.

Nori had never caused food poisoning before this incident. At the beginning of this food poisoning, a company officer remembered that the causative nori had been imported from Mainland China. The method of processing of the causative nori was not known, but might have resulted in the formation of photosensitive agents such as pyropheophorbide. Pyropheophorbide is derived from chlorophyll in plants and has caused serious food poisoning incidents in people who ate abalone ${ }^{2)}$, salted Takana (Brassica juncea $)^{3}$, and green algae powder ${ }^{4}$. The symptoms include flushing of the face, hands and fingers, swelling, pain, paralysis, and edema ${ }^{4)}$.

Numerous methods for the analysis of chlorophyll in plant tissues have been developed ${ }^{5-10)}$. Among them, reversed-phase (RP) high-performance liquid chromatography (HPLC) methods have predominated, mainly because of their ease of use, aqueous mobile phase, and the wide commercial availability of the stationary phase ${ }^{11-14)}$. The present study was undertaken to clarify the toxic components of the causative nori in this food poisoning case by mean of RP-C18 HPLC. The pyropheophorbide level in the causative dried purple laver product was found to be high, while it was not detected in other nori products. 


\section{Materials and Methods}

\section{Samples}

The causative nori (5 packages, 10 slices/package, 0.2 $\mathrm{g} /$ slice) and normal nori (10 packages) were obtained from the same company. Four samples (each containing 10 packages) produced from other companies were purchased from supermarkets. All samples were frozen at $-20^{\circ} \mathrm{C}$ until use.

\section{Patch test}

One slice of causative nori was cut into pieces, placed in a tube of $10 \mathrm{~mL}$, mixed with $5 \mathrm{~mL}$ of ethanol and then homogenized with an ultrasonic processor (Model W-380, Ultrasonic Company, New York) at $20 \mathrm{kHz}$ and 145 watts for $2 \mathrm{~min}$. The homogenate was centrifuged at $8,000 \times g$ (Hitachi SCR20B, Hitachi Co., Tokyo) for 20 $\min$ at $4^{\circ} \mathrm{C}$. The supernatant was concentrated to $1 \mathrm{~mL}$ and filter papers $\left(0.8 \mathrm{~cm}^{2}\right)$ were immersed in this solution (designated as toxic filters). To prepare control filters, the supernatant was replaced with ethanol. Five volunteers were tested on the hands. One hand was treated with one toxic and one control filters and covered with transparent rubber tape, while the other hand was similarly treated but covered with non-transparent rubber tape and clothes. The five volunteers were exposed to sunlight for $2 \mathrm{hr}$. The skin signs and their onset time were recorded according to the reported method $^{15)}$. Although acetone was better to extract photosensitive agents than ethanol, it might cause dermatitis, so ethanol was selected as the solvent for the patch test.

\section{HPLC determination}

The procedure was essentially the same as described in previous papers ${ }^{16), 17)}$, except for the mobile phase and detector. Each nori sample $(0.10 \mathrm{~g})$ was ground and homogenized in $15 \mathrm{~mL}$ of acetone with the ultrasonic processor for $2 \mathrm{~min}$. The homogenate was centrifuged as described above. The procedure was repeated three times. The supernatants were combined, concentrated and made up to $25 \mathrm{~mL}$ with acetone. This solution was filtered with a $0.22 \mu \mathrm{m}$ Millipore filter and the filtrate was subjected to HPLC using a Hitachi model L-6200 pump, a Rheodyne model 7125 syringe loading sample injector, a Lichrospher $100 \mathrm{RP}-185 \mu \mathrm{m}$ column $(250 \times 4$ mm i.d.) with a RP-18 guard column, and a Hitachi model L-7455 diode array detector. The injection volume was $20 \mu \mathrm{L}$, and the flow rate was $0.6 \mathrm{~mL} / \mathrm{min}$. The mobile phase was $100 \%$ solution A for 6 min, $70 \%$ solution $\mathrm{A}$ and $30 \%$ solution $\mathrm{B}$ for $5 \mathrm{~min}, 50 \%$ solutions $\mathrm{A}$ and $\mathrm{B}$ for $1 \mathrm{~min}, 100 \%$ solution $\mathrm{B}$ for $12 \mathrm{~min}$ and then back to $100 \%$ solution A for 8 min. Solution A was composed of ethyl acetate-methanol-water $(15: 65: 20$, $\mathrm{v} / \mathrm{v} / \mathrm{v})$ and solution B of ethyl acetate-methanol-water $(60: 30: 10, \mathrm{v} / \mathrm{v} / \mathrm{v})$. The four standards, chlorophyll $a$, pheophytin $a$, pheophorbide $a$ and pyropheophorbide $a$, were purchased from Wako Chemical Co. (Tokyo, Japan). Other chemicals (AG grade) and solvents (LC grade) were obtained from E. Merck (Darmstadt, Germany).

HPLC calibration curves for quantitative determinations were prepared using solutions of standards in acetone in the range of 5-25 (5, 10, 20 and 25$) \mu \mathrm{g} / \mathrm{mL}$ for each standard. Each standard was dissolved in acetone and the solution passed through a $0.22 \mu \mathrm{m}$ Millipore filter prior to chromatographic analysis. Then $1 \mathrm{~mL}$ of these standards was spiked into $0.1 \mathrm{~g}$ of ground normal nori sample, which was dried under a nitrogen gas flow. The concentrations of spiked standards were analyzed in triplicate to evaluate the average recoveries. The detection limit was defined as the amount of analyte giving a signal-to-noise ratio of 3 .

\section{Results}

The result of patch tests of the causative sample in the five volunteers is shown in Table 1 . Three out of five volunteers showed skin signs including redness, burning sensation, rash and itching after 5 and $10 \mathrm{~min}$ when they were treated with the toxic filters and exposed to sunlight. However, only one person showed these skin signs after $30 \mathrm{~min}$, and none showed them after 1 hr. Those without exposure to sunlight had no skin signs. These results indicate that the causative sample might contain photosensitizing agents ${ }^{18)}$.

The standard curves of chlorophyll $a$, pheophytin $a$, pheophorbide $a$ and pyropheophorbide $a$ were all linear. The equations were as follows: $Y=23717 X+19025(r=$ 0.9991) for chlorophyll $a, \quad Y=35478 X-78413 \quad(r=$ 0.9983) for pheophytin $a, \quad Y=75384 X-72418 \quad(r=$ $0.9964)$ for pheophorbide $a$, and $Y=120843 X+32160$ $(r=1.0000)$ for pyropheophorbide $a$. $X$ represents the concentration $(\mu \mathrm{g} / \mathrm{mL})$ of chlorophyll and related deriv-

Table 1. Results of Patch Test of Purple Laver Products Implicated in Food Poisoning

\begin{tabular}{|c|c|c|c|c|c|c|c|c|c|c|c|c|}
\hline \multirow{3}{*}{ Person } & \multirow{3}{*}{ Sex } & \multirow{3}{*}{ Age } & \multicolumn{10}{|c|}{ Exposure time } \\
\hline & & & \multicolumn{2}{|c|}{$5 \min$} & \multicolumn{2}{|c|}{$10 \min$} & \multicolumn{2}{|c|}{$30 \min$} & \multicolumn{2}{|c|}{$1 \mathrm{hr}$} & \multicolumn{2}{|c|}{$2 \mathrm{hr}$} \\
\hline & & & Light & Dark & Light & Dark & Light & Dark & Light & Dark & Light & Dark \\
\hline 1 & $0^{7}$ & 30 & $+*$ & - & + & - & - & - & - & - & - & - \\
\hline 2 & $\sigma^{x}$ & 27 & - & - & - & - & - & - & - & - & - & - \\
\hline 3 & 우 & 30 & - & - & - & - & - & - & - & - & - & - \\
\hline 4 & 우 & 26 & + & - & + & - & + & - & - & - & - & - \\
\hline 5 & 우 & 25 & + & - & + & - & - & - & - & - & - & - \\
\hline
\end{tabular}

$*+$ : Skin signs included redness, burning sensation, rash, and itching.

$-:$ No skin signs. 
Table 2. Recoveries of Chlorophyll $a$ and Related Derivatives Spiked into the Purple Laver Product

\begin{tabular}{lcccc}
\hline \hline \multirow{2}{*}{ Sample } & \multicolumn{3}{c}{ Recovery $(\%)$ in different standard dose } \\
\cline { 2 - 5 } & $5 \mu \mathrm{g} / \mathrm{mL}$ & $10 \mu \mathrm{g} / \mathrm{mL}$ & $20 \mu \mathrm{g} / \mathrm{mL}$ & $25 \mu \mathrm{g} / \mathrm{mL}$ \\
\hline Chlorophyll $a$ & $91.2 \pm 2.4$ & $92.1 \pm 2.1$ & $92.6 \pm 2.1$ & $93.1 \pm 1.9$ \\
Pheophytin $a$ & $87.2 \pm 3.2$ & $88.3 \pm 3.5$ & $88.6 \pm 2.9$ & $89.1 \pm 3.1$ \\
Pheophorbide $a$ & $89.2 \pm 3.5$ & $89.6 \pm 2.8$ & $89.1 \pm 3.1$ & $89.9 \pm 3.1$ \\
Pyropheophorbide $a$ & $91.2 \pm 1.5$ & $92.4 \pm 1.8$ & $92.6 \pm 1.7$ & $93.4 \pm 1.6$ \\
\hline
\end{tabular}

Data represent mean \pm S.D. $(n=3)$

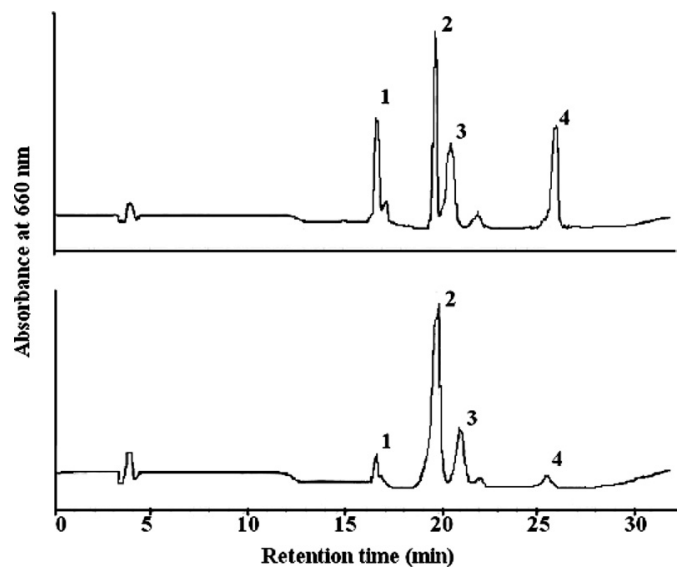

Fig. 1. HPLC chromatogram of chlorophyll $a$ and related derivatives of purple laver product extract (lower) together with standards (upper, $0.2 \mu \mathrm{g}$ for each standard), with detection at $660 \mathrm{~nm}$.

Peak 1, pheophorbide $a$; peak 2, pyropheophorbide $a$; peak 3 , chlorophyll $a$; peak 4 , pheophytin $a$.

atives, and $Y$ is the integration unit of peak area. The recoveries of chlorophyll and related derivatives spiked into the purple laver product are shown in Table 2. All recoveries were greater than $87.2 \%$. The detection limit of each compound was $0.2 \mu \mathrm{g} / \mathrm{mL}$ for test solution and $50 \mu \mathrm{g} / \mathrm{g}$ for dried purple laver product. An HPLC chromatogram of standard chlorophyll $a$ and related derivatives, along with the extract of the causative sample, is shown in Fig. 1. Chlorophyll $a$, pheophytin $a$, pheophorbide $a$, and pyropheophorbide $a$ were found to appear at retention times of 20.5, 25.8, 16.5 and $19.5 \mathrm{~min}$, respectively. The levels of chlorophyll $a$ and related derivatives in three causative samples and five other commercial products are shown in
Table 3. It was found that the causative samples contained large amounts of pheophorbide $a(851-906 \mu \mathrm{g} / \mathrm{g})$ and pyropheophorbide $a(5,460-5,624 \mu \mathrm{g} / \mathrm{g})$. These compounds were not detected in the other products.

\section{Discussion}

The $\mathrm{LD}_{50}$ values of pheophorbide $a$ were 60 and 16 $\mathrm{mg} / \mathrm{kg}$, respectively, when rats were exposed to 20,000 Lux for 1 and $2 \mathrm{hr}^{19}$. This indicated that the toxicity of pheophorbide $a$ depends on the light intensity. Matsuura et $a l^{20)}$ pointed out that pyropheophorbide $a$ was more toxic (8-fold higher toxicity) than pheophorbide $a$. The Environmental Health Bureau, Ministry of Health and Welfare, Japan, declared that the minimum dose of pheophorbide to induce photosensitivity after ingestion of chlorella was $25 \mathrm{mg} / \mathrm{man} /$ day, and the maximum allowable level of pheophorbide $a$ was set at $1,000 \mu \mathrm{g} / \mathrm{g}^{21)}$. The amount of pheophorbide $a$ in the causative nori was about $6 \mathrm{mg} / \mathrm{g}$ (6 times the allowable level), so that $4 \mathrm{~g}$ (20 slices) of the causative nori might produce toxic symptoms. However, derivatives of pheophorbide $a$ might be further produced in the consumer by chlorophyllase when the causative nori was digested. In addition, pyropheophorbide $a$ was major component in the causative nori and is 8 -folds more toxic than pheophorbide $a$. Hence, less than $4 \mathrm{~g}$ of the causative nori might induce photosensitivity.

Judging from the high concentrations of pheophorbide $a$ and pyropheophorbide $a$ in the causative sample and the symptoms of the patients and volunteers, the causative agents concluded to be the photosensitizers pheophorbide $a$ and pyropheophorbide $a$, in the food poisoning incident which occurred in Taiwan in May, 2001. Pheophorbide $a$ and pyropheophorbide $a$ might

Table 3. Levels of Chlorophyll $a$ and Related Derivatives in Purple Laver Products

\begin{tabular}{|c|c|c|c|c|}
\hline \multirow{2}{*}{ Sample No. } & \multicolumn{4}{|c|}{ Content $(\mu \mathrm{g} / \mathrm{g})$} \\
\hline & Chlorophyll $a$ & Pheophytin $a$ & Pheophorbide $a$ & Pyropheophorbide $a$ \\
\hline $1 * 1$ & $801 \pm 12^{* 2}$ & $1154 \pm 14$ & $890 \pm 12$ & $5460 \pm 73$ \\
\hline 2 & $846 \pm 13$ & $1206 \pm 13$ & $851 \pm 11$ & $5624 \pm 63$ \\
\hline 3 & $786 \pm 15$ & $1184 \pm 11$ & $906 \pm 13$ & $5489 \pm 54$ \\
\hline 4 & $1495 \pm 14$ & $1255 \pm 10$ & ND & ND \\
\hline 5 & $1040 \pm 3$ & $1195 \pm 24$ & ND & ND \\
\hline 6 & $981 \pm 2$ & $1217 \pm 3$ & ND & ND \\
\hline 7 & $778 \pm 13$ & $1208 \pm 22$ & ND & ND \\
\hline 8 & $1074 \pm 11$ & $1272 \pm 29$ & ND & ND \\
\hline
\end{tabular}

*1 Samples 1, 2 and 3 were implicated in food poisoning and collected from the victims, and other samples were obtained from markets.

*2 Data represent means \pm S.D. $(n=3)$. ND means less than $50 \mu \mathrm{g} / \mathrm{g}$. 
have been generated by improper processing of the dried purple laver product, such as improper storage of the fresh purple laver.

It is generally accepted that pheophorbide $a$ and pyropheophorbide $a$ are easily formed by various factors including temperature, sunlight, $\mathrm{O}_{2}$, moisture, and catalysts, or by frying and steaming. Chlorophylls may be transformed into pheophytins via acid processing, leading to pheophorbides by further elimination of the phytol group. On the other hand, chlorophyll may be directly transformed into chlorophyllides via the chlorophyllase reaction, which produces pheophorbides by elimination of magnesium ion under acidic conditions. Once pheophorbides are formed, they are easily converted to pyropheophorbides by heating ${ }^{22), 23)}$.

Chlorophyllase has an optimal temperature of about $70^{\circ} \mathrm{C}$ and shows higher affinity for chlorophyll $a$ than for chlorophyll $b^{24)}$. The activity of chlorophyllase varies depending on the species of source plant ${ }^{25)}$, water activity $^{8)}$, $\mathrm{pH}$ and solvent ${ }^{26)}$. Methods for preventing chlorophyll degradation during processing include controlling the $\mathrm{pH}$, decreasing the exposure time to high temperature, preventing the loss of magnesium ion, and adding antioxidants ${ }^{23)}$. The formation mechanism of pheophorbides and pyropheophorbides in dried purple laver and the characteristics of chlorophyllase in fresh purple laver are being investigated.

\section{Acknowledgments}

This study was supported by a grant from the National Science Council, Taiwan, R.O.C.

\section{References}

1) Ito, K., Nishizawa, K., Tsujino, I., Noda, H., "Biochemistry and Utilization of Marine Algae" Koseishai-Koseikaku, Tokyo, 1983.

2) Hashimoto, Y., Tsutsumi, J., Isolation of a photodynamic agent from the liver of abalone Haliotis discus hannai. Nippon Suisan Gakkaishi, 27, 859-866 (1961).

3) Yamada, K., Nakamura, N., Photodynamic agent of pickled green. Nippon Eiyo Shokuryo Gakkaishi, 25, 466471 (1972).

4) Kato, T., Yamada, K., Relationship between appearance of photosensitization and total pheophorbide level in spirulina powder. Shokuhin Eiseigaku Zasshi (J. Food Hyg. Soc. Japan), 36, 632-634 (1995).

5) Jeffrey, S. W., Profiles of photosynthetic pigments in the ocean using thin-layer chromatography. Mar. Biol., 26, 101-110 (1974).

6) Holm-Hansen, O., Chlorophyll $a$ determination: improvements in methodology. Oikos, 30, 438-447 (1978).

7) Sudo, T., Igarashi, S., Homogeneous liquid-liquid extraction method for spectrofluorimetric determination of chlorophyll $a$. Talanta, 43, 233-237 (1996).

8) Hirata, K., Hirokado, M., Uematsu, Y., Sadamasu, Y., Yasuda, K., Kazama, M., Suzuki, S., Determination of chlorophyll degradation products in chlorophyll color preparations. Shokuhin Eiseigaku Zasshi. (J. Food Hyg. Soc. Japan), 38, 155-160 (1997).

9) Maeda, Y., Adachi, M., Shimokawa, K., Pyropheophorbide $a$ catabolic pathway in Citrus unshiu fruits. Bull. Fac. Agric., 45, 37-42 (1998).
10) Moberg, L., Karlberg, B., Blomqvist, S., Larsson, U., Comparison between a new application of multivariate regression and current spectroscopy methods for the determination of chlorophylls and their corresponding pheopigments. Anal. Chim. Acta, 411, 137-143 (2000).

11) Suzuki, Y., Tanabe, K., Sioi, Y., Determination of chemical oxidation products of chlorophyll and porphyrin by high-performance liquid chromatography. J. Chromatogr. A, 839, 85-91 (1999).

12) Mantoura, R. F. C., Llewellyn, C. A., The rapid determination of algal chlorophyll and carotenoid pigments and their breakdown products in natural waters by reversephase high-performance liquid chromatography. Anal. Chim. Acta, 151, 297-314 (1983).

13) Minguez-Mosquera, M. I., Gandul-Rojas, B., GallardoGuerrero, M. L., Rapid method of quantification of chlorophylls and carotenoids in virgin olive oil by highperformance liquid chromatography. J. Agric. Food Chem., 40, 60-63 (1992).

14) Psomiadou, E., Tsimidou, M., Simultaneous HPLC determination of tocopherols, carotenoids and chlorophylls for monitoring their effect on virgin olive oil oxidation. J. Agric. Food Chem., 46, 5132-5138 (1998).

15) Galasso, F., Altamura, V., Sbano, E., Effects of topical testosterone propionate on the positive nickel patch test. J. Dermatol. Sci., 13, 76-82 (1996).

16) Liu, H. W., Fu, H. Y., Huamg, T. C., Development of HPLC method for determination of pheophorbide a concentration in chlorella tablet. J. Chin. Agr. Chim. Acta, 31, 785792 (1993)

17) Moreau, R., Powell, M. J., Agnew, J., Young, D. H., Chlorophyll-derived porphyrins co-chromatograph with phospholipids in high-performance liquid chromatographic separations of plant lipid classes. Phytochem. Anal., 9, 1-4 (1998).

18) Concon, J. M., Food Toxicology Part A "Principles and Concepts" Marcel Dekker, New York, 1988.

19) Endo, H., Hosoya, H., Koyana, T., Isolation of 10hydroxypheophorbide $a$ as $a$ photosensitizing pigment from alcohol-treated Chlorella cells. Agric. Biol. Chem., 46, 2,183-2,193 (1982).

20) Matsuura, E., Fukimbara, T., Kawahara, H., Ito, H., Studies on photodynamic action of chlorophyll derivatives phototoxicity of pheophorbide $a$ on rats. Kitasato Arch. Exp. Med., 61, 201-213 (1988).

21) Uchiyama, S., Pheophorbide $a$ and Related Substances. In: Standard Methods of Analysis in Food Safety Regulation: Chemistry, Uchiyama, M. (eds.), Japan Food Hygiene Association, Tokyo, 1991, p. 287-292.

22) Schwartz, S. J., Lorenzo, T. V., Chlorophyll stability during continuous aseptic processing and storage. J. Food Sci., 56, 1,059-1,062 (1991).

23) Heaton, J. W., Marangoni, A. G., Chlorophyll degradation in processed foods and senescent plant tissues. Trends Food Sci. Technol., 7, 8-15 (1996).

24) Schartz, S. J., Von Elbe, J.H., Kinetics of chlorophyll degradation to pyropheophytin in vegetables. J. Food Sci., 48, 1,303-1,306 (1983).

25) Jones, I. D., White, R. C., Gibbs, E., Influence of blanching or brining treatments on the formation of chlorophyllides, pheophytins, and pheophorbides in green plant tissue. J. Food Sci., 28, 437-439 (1963).

26) Minguez-Mosquera, M. I., Gandul-Rojas, B., GallardoGuerrero, L., De-esterification of chlorophylls in olives by activation of chlorophyllase. J. Agric. Food Chem., 41, 2,254-2,258 (1993). 